\title{
A Bioequivalence Study Comparing Two Formulation of Emtricitabine Capsules
}

\author{
A.T.Bapuji ${ }^{\star}$, M.Nagesh, D.Ramaraju, Syed Syedba, \\ Ravi Kiran, S.Ravinder and D.Chandrapal reddy
}

Department of Clinical Pharmacology, APL research centre, (Aurobindo Pharma) Hyderabad

\begin{abstract}
This investigation was carried out to evaluate the bioavailability of emtricitabine $200 \mathrm{mg}$ capsules (Test) of Aurobindo Pharma Ltd, India, relative to reference product, Emtriva 200mg capsules, manufactured by Gilead Sciences, Inc., USA. The bioavailability study was carried out on 36 healthy male volunteers who received a single dose of emtricitabine $200 \mathrm{mg}$ of the test $(\mathrm{T})$ and the reference ( $\mathrm{R}$ ) products in the fasting state, in a randomized, balanced, 2-way cross-over design. After dosing, serial blood samples were collected for a period of 48 hours. Plasma obtained from blood was analyzed for emtricitabine by a sensitive and validated simultaneous liquid-chromatographic and mass-spectrometric (LC-MS/ MS) assay. The maximum plasma concentrations $\left(\mathrm{C}_{\max }\right)$, area under the plasma concentration-time curve up to the last measurable concentration $\left(\mathrm{AUC}_{0-\mathrm{t}}\right)$, and to infinity $\left(\mathrm{AUC}_{0-\alpha}\right)$ and the time to maximum concentration $\left(\mathrm{t}_{\max }\right)$ were analyzed statistically. The parametric confidence intervals $(90 \%)$ were calculated. It was found that the test/ reference $(\mathrm{T} / \mathrm{R})$ ratios for the pharmacokinetic parameters $\left(\mathrm{AUC}_{0-\mathrm{t}}\right),\left(\mathrm{AUC}_{0-\alpha}\right)$ and $\left(\mathrm{C}_{\max }\right)$ were well within the Bioequivalence acceptance range of $80-125 \%$ as per international regulatory guidelines. Therefore, the two formulations were considered to be bioequivalent.
\end{abstract}

Keywords: Emtricitabine; Bioequivalence-study pharmacokinetics statistics

\section{Introduction}

Emtricitabine (FTC; Emtriva), a potent doxycytidine nucleoside reverse transcritase inhibitor is used to treat human immunodeficiency virus (HIV) infection. In adults, FTC has demonstrated linear kinetics over a wide dose range and FTC 200mg once a day is the recommended therapeutic dose. Emtricitabine is consistently (4-10 times) more patent than lamivudine (3TC) in vitro against laboratory strains and primary clinical isolates of HIV (Schinazi et al., 1992; Schinazi et al., 1993; Tisdale et al., 1993). As a nucleoside reverse transcriptase inhibitor (NRTI), emtricitabine is readily anabolized by cellular enzymes in a step wise fashion to form its mono phosphate, diphosphate, and finally 5 '-triphosphate (TP) form, the active intracellular moiety that inhibits HIV-1 reverse transcriptase (RT) and HBV DNA polymerase (Wilson et al., 1993; Furman et al., 1995; Davis et al., 1996).

Emtricitabine is rapidly and extensively absorbed followed oral administration, with peak plasma concentration occurring within $1.5 \mathrm{hr}$ of dosing and with an oral bioavailability $>90 \%$ (Wang et al., 2001; Gish et al., 2002). Emtricitabine disposition follows linear kinetics with small intersubject variability and plasma emtricitabine concentrations increased dose propotionally over a wide dose range (100-1200mg) (Wang et al., 1995). Emtricitabine does not appreciably bind to plasma proteins $(<4 \%)$ and is primarily eliminated from plasma as unchanged drug in urine (about $65-70 \%$ of an oral dose), with a plasma elimination half-life of 8-10hr (Wang et al., 2001).

A new generic formulation has been developed having the same composition as innovator brand and the method of manufacture is wet granulation.

A single dose $200 \mathrm{mg}$ of emtricitabine has been evaluated in this study. The pharmacokinetics of emtricitabine were evaluated in 36 healthy male volunteers. The aim of this study was to determine the Bioequivalence and to compare the pharmacokinetics of two formulations (innovator vs. generic) of emtricitabine 200mg capsules.

\section{Materials and Methods}

\section{Study design}

This study was an open label, randomized, two-treatment, twosequence, two-period, cross-over, single-dose comparative oral bioavailablity study of emtricitabine $200 \mathrm{mg}$ capsules (Test) of Aurobindo Pharma Ltd., India and Emtriva 200mg capsules (Reference) of Gilead Sciences Inc., USA.

All study medications were kept in a pharmacy and temperature and humidity were monitored continuously. A SAS generated randomization code was used to ensure balanced permutation of the treatments. Both test and reference formulations were administered with $240 \mathrm{ml}$ of water in one of their periods of crossover that was separated by a washout period of 8 days. The subjects were confined to the clinic through out the 24-hour postdose and returned for the 36 and 48-hour during each study period. During the trial, the subjects were to remain ambulatory or sealed upright for the first 4 hours after drug administration. During housing, post-dose meals were identical for both periods of the study. Lunch, dinner and snack were served at 4.0, 8.0 and 13.0 hours, respectively, after dosing. As per the FDA Guide-

*Corresponding author: A.T.Bapuji, Clinical pharmacology department, APL research centre, Survey no.313, Bachupally village, Quthubullapur mandal, Hyderabad, 500072; E-mail: bapuji@aurobindo.com

Received December 16, 2009; Accepted January 21, 2010; Published January 21, 2010

Citation: Bapuji AT, Nagesh M, Ramaraju D, Syedba S, Kiran R, et al. (2010) A Bioequivalence Study Comparing Two Formulation of Emtricitabine Capsules. J Bioequiv Availab 2: 011-014. doi:10.4172/ jbb. 1000023

Copyright: @ 2010 Bapuji AT, et al. This is an open-access article distributed under the terms of the Creative Commons Attribution License, which permits unrestricted use, distribution, and reproduction in any medium, provided the original author and source are credited. 
Citation: Bapuji AT, Nagesh M, Ramaraju D, Syedba S, Kiran R, et al. (2010) A Bioequivalence Study Comparing Two Formulation of Emtricitabine Capsules. J Bioequiv Availab 2: 011-014. doi:10.4172/jbb.1000023

lines, water was not permitted from 1 hour before dosing until 1 hour following dosing, but it was allowed at all other times.

The protocol and informed consent forms (ICFs) were reviewed and approved prior to study initiation by an independent Institutional Review Board (IRB). The IRB operates in accordance with the principles and requirements described in the US Code of Federal Regulations (21 CFR Part 56). All subjects read and signed the ICF prior to study initiation. This clinical trial was conducted in accordance with the Declaration of Helsinki, good Clinical Practice guidelines.

\section{Subjects and treatments}

The subjects were screened within 28 days prior to study enrolment. The screening procedure included medical histories and demographic data, including name, sex, age, race, body weight $(\mathrm{kg})$, height $(\mathrm{cm})$, and tobacco use. Healthy adult male volunteers were to fulfill all of the following inclusion criteria to be eligible for participation in the study. Males with a minimum age of 18 years and body mass index greater than or equal to $18.04 \mathrm{~kg} / \mathrm{m}^{2}$ and less than or equal to $25.00 \mathrm{~kg} / \mathrm{m}^{2}$. These criteria were used for the selection of healthy volunteers since they are associated with the lowest mortality rate in the population as per the Metropolitan Life Insurance Company. All subjects were subjected to a vital signs measurement, a 12-lead electrocardiogram (ECG), and laboratory tests to evaluate their hematologic, hepatic and renal functions, prior to study enrolment, the clinical investigator reviewed the screening data and performed the physical examinations. The subjects were not to consume any food and beverages containing xanthines or alcohol (48 hours before dosing and throughout the period of sample collection), grapefruit ( 72 hours before dosing and throughout the study), or vitamins (throughout the confinement period). Subjects were to be nonsmokers; medication (including herbal and over-the-counter products) was prohibited for the 14 days preeding the study and also during the study. On the evening prior to each dosing, all subjects were screened for cocaine, cannabinoids, benzodiazepines, Opioids, Amphetamines, barbiturates and alcohol. A total of 36 healthy adult male volunteers who had satisfied the above screening criteria were admitted to the study center in the evening before dosing (Day-1), then they were assigned to each treatment sequence as per the randomization scheme. All the subjects received doses of $200 \mathrm{mg}$ emtricitabine capsules on the dosing day.

Adverse events were monitored throughout the study, until resolution or loss to follow-up. Adverse events were described in terms of severity, scriousness, outcome, action, frequency and relationship to treatments. The principal investigator or sub-investigator was on-site, within the proximity of the subject confinement area for first 6 hours after drug administration. Subjects were instructed to inform the study physician and/or nurses of any adverse events that occurred during the study.

\section{Blood sample collection}

Blood samples (1 x $6 \mathrm{ml}$ ) for emtricitabine analysis were collected in EDTA vacutainers at hour 0.00 (pre-dose) and at 0.25 , $0.50,0.75,1.0,1.25,1.50,1.75,2.0,2.25,2.50,3.0,4.0,6.0$, 8.0, 10.0, 12.0, 16.0, 20.0, 24.0, 36.0 and 48.0 hours post dose. Immediately, blood samples were centrifuged under refrigeration and then plasma was separated and stored at $-70^{\circ} \mathrm{C} \pm 10^{\circ} \mathrm{C}$ at the clinical unit of Trident Life sciences Ltd and then transferred to the bioanalytical facility of Trident life sciences Ltd under frozen condition and then samples were stored at $-70^{\circ} \mathrm{C}$ or below until sample analysis.

\section{Analytical Methods}

Plasma concentrations of emtricitabine were assessed by a simultaneous method using high-performance liquid chromatography with mass spectrometry detection (LC-MS/MS). Method validation was performed according to the current international approach and the applicable regulations regarding bioanalytical method validation (FDA, 2001). An aliquot of human plasma containing the analyte and the internal standard was extracted using a solid-phase extraction (SPE). The internal standard for emtricitabine assay was lamivudine. $50 \mu \mathrm{l}$ of the internal standard working solution (lamivudine in 1:1 methanol: water solution) were added to $300 \mu \mathrm{l}$ of each plasma sample. After vortexing the tubes, $100 \mu \mathrm{l}$ of diluted Ortho phosphoric acid solution was added and the tubes were again vortexed. The mixture was transferred to preconditioned Oasis HLB (1CC/30mg) extraction cartridges. The analytes were eluted off from the extraction cartridge with $1 \mathrm{ml}$ acetonitrile. Eluent was evaporated and reconstituted with the mobile phase (0.1\% formic acid ( $\mathrm{pH} 2.6)$ : acetonitrile:Methanol (10:27:63 v/v)). The extracts were injected into the LC-MS/MS system equipped with AB/MDS Sciex API3000 mass spectrometer. Positive ions were monitored in the multiple reaction-monitoring (MRM) mode. The following ion transitions using analyst 1.4.2 were monitored 248.1/130.2 and 230.4/112.1 emtricitabine and internal standard respectively.

Linearity for emtricitabine was assessed by plotting area ratios versus standard concentrations and using a linear regression weighted $1 /$ concentration 2 . Analytical range for emtricitabine was $5.03-4008.47 \mathrm{ng} / \mathrm{ml}$. Inter-and intrabatch precision and accuracy were assessed at low, medium and high QC concentration level. For emtricitabine interbatch precision (CV\%) results were less than $4.3 \%$ and accuracy (\%theoretical) results ranged between 98.7 and $102.1 \%$ Intrabatch precision $(\mathrm{CV} \%)$ results were less than $5.9 \%$ and accuracy (\%theoretical) results ranged between 98.6 and $103.7 \%$.

\section{Pharmacokinetics and statistical analysis}

The following PK parameters were calculated using validated PK software (WinNonlinversion 5.0.1). The area under the curve from time zero to the last measurable concentration $\left(\mathrm{AUC}_{0-\mathrm{t}}\right)$ using the linear trapezoidal rule, the area under the curve extrapolated to infinity $\left(\mathrm{AUC}_{0-\mathrm{t}}+\mathrm{C}_{\text {last }} / \mathrm{k}_{\mathrm{el}}\right.$, where $\mathrm{C}_{\text {last }}$ is the last measurable plasma concentration), the maximum plasma concentration $\left(\mathrm{C}_{\max }\right)$, and the time to maximum plasma concentration $\left(\mathrm{t}_{\max }\right)$, the terminal rate constant of elimination $\left(\mathrm{k}_{\mathrm{el}}\right)$ and terminal elimination half-life $\left(\mathrm{t}_{1 / 2}\right)$. The ratio of $\mathrm{AUC}_{0-\mathrm{t}}-\mathrm{AUC}_{0-\alpha}$ $\left(\mathrm{AUC}_{0-\mathrm{t}} / \mathrm{AUC}_{0-\alpha}\right)$ as well as the extrapolated area of the curve $\left(\mathrm{AUC}_{0-\alpha}=\left(\mathrm{AUC}_{0-\alpha}-\mathrm{AUC}_{0-\mathrm{t}}\right) / \mathrm{AUC}_{0-\alpha}\right)$ were calculated as percentage. In addition, the oral clearance $(\mathrm{Cl} / \mathrm{F})$ was calculated as Dosc/AUC ${ }_{0-\alpha}$. Concentration values below the LOQ of the assay for emtricitabine $(5.03 \mathrm{ng} / \mathrm{ml})$ were set to zero. Analyses of variance (ANOVA) were performed on In-transformed $\mathrm{AUC}_{0-\mathrm{t}}$, $\mathrm{AUC}_{0-\alpha}$ and $\mathrm{C}_{\text {max }}$ parameters. The ANOVA model included sequence, subjects nested within sequence, period and drug formulation as factors according to regulatory guidance on 


\section{Journal of Bioequivalence \& Bioavailability - Open Access}

JBB/Vol.2 Issue 1

Bioequivalence. A statistical analysis was performed using the SAS $^{\circledR}$ GLM procedure (SAS ${ }^{\circledR}$ system for windows ${ }^{\circledR}$ release 9.1.3) Geometric least-square means (LSM) as well as ratio of LSM with corresponding 90\% confidence intervals (CI's) for the generic and innovator formulations were calculated. In addition, nonparametric methods were used to assess differences in median values of $\mathrm{t}_{\text {max }}$ between the two formulations and $90 \%$ CI's were constructed.

\section{Results}

\section{Demographics and safety results}

36 male subjects representing the general population were enrolled in this study, but only 32 subjects completed the study and their demographics are as follows, mean age, height and weight were 26.81(19-40) years, 165.06(154-186) $\mathrm{cm}$ and 58.72 (50-72) kg, respectively. The subjects' mean BMI was 21.56 $(18.04-25.00) \mathrm{kg} / \mathrm{m}^{2} .4$ subjects withdrew from the study prior to receiving the formulation (1 subject for test and 3 subjects for reference) due to absent for the participation in period 2 and positive for drugs of abuse. No deaths or serious adverse events occurred during conduct of this study. None of the subjects shown any adverse events except post study laboratory abnormalities.

\section{Pharmacokinetics and statistics}

Mean plasma concentration profiles of emtricitabine under linear over the 48-hour pharmacokinetic study are presented in Fig-

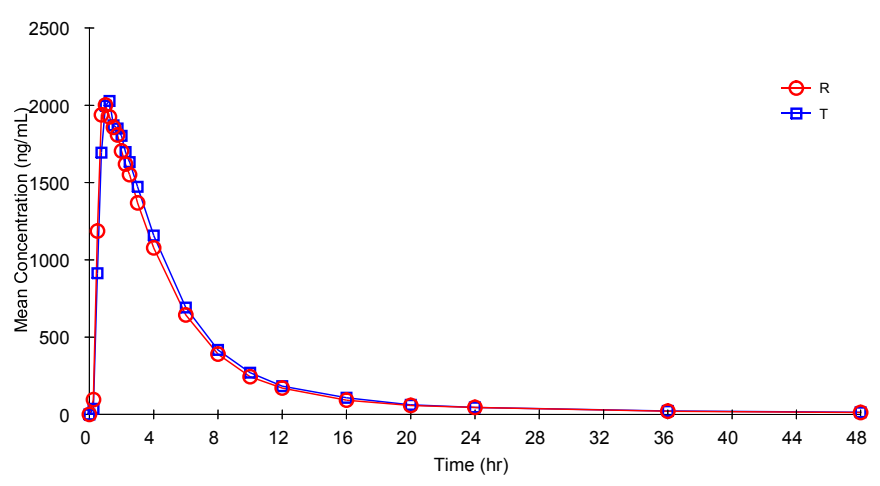

Figure 1: Linear mean plot of Emtricitabine $200 \mathrm{mg}$ capsule concentration Vs time under fasting conditions ure 1. Overall, mean plasma concentrations of emtricitabine peaked rapidly and then declined in a monoexponential manner, with most plasma concentration values falling below the LOQ of the assay at 48 hours postdose. Values below the LOQ were set to zero for pharmacokinetic analysis. A8-day washout period between treatments was sufficient since all predose concentration levels of emtricitabine were below the LOQ of the assay in Period 2. Mean plasma concentrations of emtricitabine following oral administration of these formulations were almost superimposable during the early absorption, distribution and elimination phases of the products Ratios of $\mathrm{AUC}_{0-\mathrm{t}} / \mathrm{AUC}_{0-\alpha}$ for all the subjects found to be more than $80 \%$ indicating the blood samples collected adequately characterized the pharmacokinetic profile of the drug. In addition, a sample size of 32 subjects provided $100 \%$ power to detect a difference of at least $20 \%$ in $\mathrm{C}_{\text {max }}, \mathrm{AUC}_{0-\mathrm{t}}$ and $\mathrm{AUC}_{0-\alpha}$ between the two treatments.

The statistical results of primary pharmacokinetic parameters of emtricitabine are presented in Table 1. The ANOVA probability values for the pharmacokinetic parameters $\mathrm{C}_{\max }, \mathrm{AUC}_{0-\mathrm{t}}$ and $\mathrm{AUC}_{0-\alpha}$ are presented in Table 2.The Geometric mean ratios of test and references for $\mathrm{C}_{\max }, \mathrm{AUC}_{0-\mathrm{t}}$ and $\mathrm{AUC}_{0-\alpha}$ were 99.37, 104.91 and $105.13 \%$ for emtricitabine and are presented in Table 3. The $90 \%$ CIs for emtricitabine were within $80.0-125.0 \%$, suggesting the generic formulation developed by Aurobindo is bioequivalent with Emtriva of Gilead Sciences Inc., USA. The intra subject coefficient of variation for both untransformed and Lntranformed pharmacokinetic parameters $\mathrm{C}_{\max }, \mathrm{AUC}_{0-\mathrm{t}}$ and $\mathrm{AUC}_{0-\alpha}$ are presented in Table 4.

\section{Discussion}

The current investigation demonstrates both generic and innovator capsule formulations displayed similar rate and extent of bioavailability of emtricitabine. The Tmax for reference is found to be $1.25 \mathrm{hr}$ and for reference it is $1.00 \mathrm{hr}$. The Tmax is comparable. The Cmax is found to be consistent both for test and reference indicating the attainment of body peak levels similarly. Cmax was found to be $17 \%$ inter subject variation for test preparation and $24.77 \%$ for reference preparation. However the mean data is very much comparable. For the $\mathrm{AUC}_{0-\mathrm{t}}$ parameter the results found to be similar and not much difference in inter subject variability and similarly for $\mathrm{AUC}_{0-\alpha}$. The $\mathrm{T}_{1 / 2}$ values are

\begin{tabular}{|c|c|c|c|}
\hline \multirow{2}{*}{ Parameters } & \multicolumn{2}{|c|}{ Treatments } & \multirow{2}{*}{ T/R Ratio of LSM $(90 \%$ CI $)$} \\
\hline & Test(T) & Reference(R) & \\
\hline \multicolumn{4}{|c|}{ Emtricitabine } \\
\hline Cmax (ng/mL) & $2212.63(17.13 \%)$ & $2255.15(24.77 \%)$ & $99.37(93.42-105.70)$ \\
\hline $\mathrm{AUC}_{0-\mathrm{t}}(\mathrm{ng} * \mathrm{hr} / \mathrm{mL})$ & $11626.29(14.57 \%)$ & $11108.22(14.48 \%)$ & $104.91(102.23-107.65)$ \\
\hline $\operatorname{AUC}_{0-\infty}(\mathrm{ng} * \mathrm{hr} / \mathrm{mL})$ & $11884.72(14.59)$ & $11332.16(14.48)$ & $105.13(102.43-107.90)$ \\
\hline $\mathrm{T}_{1 / 2}(\mathrm{hr})$ & $12.75(14.84 \%)$ & $12.28(14.39 \%)$ & \\
\hline Tmax (hr) & $1.25(0.75-2.25)^{\mathrm{a}}$ & $1.00(0.5-2.25)^{\mathrm{a}}$ & \\
\hline
\end{tabular}

${ }^{a}$ Median (range)

Table 1: Summary Statistics of Emtricitabine.

\begin{tabular}{|c|c|c|c|c|}
\hline \multicolumn{2}{|c|}{ ANOVA p-value } & $\mathbf{C}_{\text {max }}$ & AUC $_{\text {0-t }}$ & AUC $_{\text {0-inf }}$ \\
\hline \hline \multirow{3}{*}{ Untransformed } & Sequence & 0.6051 & 0.5433 & 0.5201 \\
\cline { 2 - 5 } & Period & 0.2700 & 0.0028 & 0.0021 \\
\cline { 2 - 5 } & Treatment & 0.6886 & 0.0029 & 0.0020 \\
\hline \multirow{3}{*}{ Lntransformed } & Sequence & 0.8696 & 0.4261 & 0.4123 \\
\cline { 2 - 5 } & Period & 0.3438 & 0.0024 & 0.0020 \\
\cline { 2 - 5 } & Treatment & 0.8635 & 0.0037 & 0.0027 \\
\hline
\end{tabular}

Table 2: ANOVA. 
Citation: Bapuji AT, Nagesh M, Ramaraju D, Syedba S, Kiran R, et al. (2010) A Bioequivalence Study Comparing Two Formulation of Emtricitabine Capsules. J Bioequiv Availab 2: 011-014. doi:10.4172/jbb.1000023

\begin{tabular}{|c|c|c|c|c|c|}
\hline \multirow{2}{*}{ Parameters } & Geometric Mean & (T/R) Ratio & 90\% Confidence Interval & Power \\
\cline { 2 - 6 } & Test & Reference & $(\boldsymbol{\%})$ & $(\%)$ & 99.99 \\
\hline $\mathbf{C}_{\mathbf{m a x}}$ & 2180.62 & 2194.4 & 99.37 & $93.42-105.70$ & 100.00 \\
\hline $\mathbf{A U C}_{\mathbf{0}-\mathbf{t}}$ & 11537.13 & 10997.41 & 104.91 & $102.23-107.65$ & 100.00 \\
\hline AUC $_{\mathbf{0}-\boldsymbol{\infty}}$ & 11794.07 & 11218.55 & 105.13 & $102.43-107.90$ & \\
\hline
\end{tabular}

Table 3: $90 \%$ Confidence Intervals.

\begin{tabular}{|l|l|l|}
\hline \multirow{2}{*}{ Parameter } & Intra Subject CV\% & Ln transformed \\
\cline { 2 - 3 } & Untransformed & 14.60 \\
\hline $\mathbf{C}_{\mathbf{m a x}}$ & 16.00 & 6.08 \\
\hline $\mathbf{A U C}_{\mathbf{0 - \mathrm { t }}}$ & 5.97 & 6.12 \\
\hline $\mathbf{A U C}_{\mathbf{0}-\boldsymbol{\infty}}$ & 5.99 & \\
\hline
\end{tabular}

Table 4: Intra Subject CV\%.

also comparable and in the elimination phase there is no variation.

The statistical analysis was carried out for both untransformed and $\log$ transformed data. The data is showing statistical equivalence for the important pk parameters i.e. $\mathrm{C}_{\max }, \mathrm{AUC}_{0-\mathrm{t}}$ and $\mathrm{AUC}_{0-}$ $\alpha$. The $90 \%$ confidence intervals are well within the limits and can be acceptable by any regulatory agency. A power of $100 \%$ was achieved for the PK parameters. The intra subject $\mathrm{CV}$ was found to be $14.60 \%$ for Cmax, $6.08 \%$ for $\mathrm{AUC}_{0-\mathrm{t}}$ and $6.12 \%$ for $\mathrm{AUC}_{0-\alpha}$ for log transformed data. Based on the results the generic is found to be bioequivalent and can be substituted for brand product.

Although the generic formulation does a significant cost reduction at this point of time the exact figures are not available.

The present investigation has been successfully conducted in 36 healthy male volunteers. During the clinical study there were no significant protocol/SOP deviations and adverse events were mild in nature. The subjects well tolerated the study medication. The biological samples were successfully analysed by LCMS/ MS. The quality control data is found to be consistent and precise. As a result, the generic capsule formulation of emtricitabine developed by Aurobindo Pharma Limited should be equally effective and safe as the innovator product of Emtriva manufactured by Gilead Sciences Inc., USA and is expected to produce considerable cost-savings in the AIDS population worldwide.

\section{References}

1. Davis MG, Wilson JE, Van Draanen NA, Miller WH, Freeman GA, et al. (1996) DNA polymerase Activityof hepatitis B virus particles: Differential inhibition by L-enantiomers of nucleoside analogs. Anti-viral Res 30: 133145. » CrossRef » PubMed » Google Scholar

2. FDA.Guidance for industry: bioanalytical method validation. U.S. (2001) Department of Health and human services. Food and drug admin-istration, Center for Drug Evaluation and Research: Rockville p1-22. »CrossRef » PubMed » Google Scholar
3. Furman PA, Reardon JE, Painter GR (1995) The role of absolute configuration in the anti-HIV and anti-HBV activity of nucleoside analogs. Antiviral Chem Chemother 6: 345-355. » CrossRef » PubMed » Google Scholar

4. Gish RG, Leung NWY, Wright TL, Wang C, Corey L, et al. (2002) A dose ranging study of the pharmacokinetics, safety and preliminary antiviral activity of emtricitabine in adults with HBV infection. Antimicrob Agents Chemother 46: 1734-1740. » CrossRef » PubMed » Google Scholar

5. Schinazi RF, McMillan A, Cannon D, Mathis R, Loyd RM, et al. (1992) Selective inhibition of human immunodeficiency viruses by racemates and enantiomers of cis-5-fluoro-1-[2-(hydroxymethyl)-1,3-oxathiolan-5yl]cytosine. Antimicrob Agents Chemother 36: 2423-2431. » CrossRef » PubMed $»$ Google Scholar

6. Schinazi RF, Lloyd RM, Nguyen MH, Cannon cL, McMillan A, et al. (1993) Characterization of human immunodeficiency viruses resistant to oxathiolane-cytosine. Antimicrob Agents Chemother 37: 875-881. »CrossRef » PubMed » Google Scholar

7. Tisdale M, Kemp SD, Parry NR, Larder BA (1993) Rapid in vitro selection of human immunodeficiency virus type 1 resistant to $3^{\prime}$ thiacytidine inhibitors due to a mutation in the YMDD region of reverse transcriptase. Proc Natl Acad Sci 90: 5653-5656. » CrossRef » PubMed » Google Scholar

8. Wang LH, Gardner P, Frick LW, Noblin JE, Blum MR (1995) Pharmacokinetics and safety of 524W91 following single oral administration of escalating doses in HIV-infected volunteer. Program and Abstracts of the $35^{\text {th }}$ Interscience3 Conference on Antimicrobial Agents and Chemotherapy, San Francisco, CA p24. »CrossRef » PubMed » Google Scholar

9. Wang LH, Blum MR, Hui J, Hulett L, Chittick G (2001) Lack of significant pharmacokinetic interactions between emtricitabine (Coviracil) and other nucleoside antivirals in healthy volunteers, Program and Abstracts of the 41 st Interscience Conference on Antimicrobial Agents and Chemotherapy, Chicago, IL p18. » CrossRef » PubMed » Google Scholar

10. Wilson JE, Martin JL, Borroto-Esodo K, Hopkins S, Painter G, et al. (1993) The 5'- triphosphates of the (-) and (+) enantiomers of cis-5-fluoro-1-[2hydroxymethyl-1,3-xathiolane-5-yl]cytosine equally inhibit human immunodeficiency virus type 1 reverse transcriptase. Antimicrob Agents Chemother 37: 1720-1722. » CrossRef » PubMed » Google Scholar 